\title{
PENGEMBANGAN SISTEM AUTENTIKASI PENDAFTARAN ONLINE PASIEN PADA KLINIK CATUR ARIWIBOWO MENGGUNAKAN SMS GATEWAY
}

\author{
${ }^{1}$ Siti Sari, ${ }^{2}$ Dwi Sakethi, ${ }^{3}$ Rizky Prabowo \\ 1,2,3 Jurusan Ilmu Komputer FMIPA Universitas Lampung \\ Jalan Prof. Sumantri Brojonegoro No. 1 Bandar Lampung 35145 \\ 1'sitisari001@gmail.com, ${ }^{2}$ dwijim@fmipa.unila.ac.id, ${ }^{3}$ rizky.prabowo@fmipa.unila.ac.id
}

\begin{abstract}
Catur Ariwibowo Clinic is one of health services located in Pringsewu district. Registration services that already exist in the clinic is still conventional, by recording on the book that causes stacking of paper in filing cabinets. One of the utilization of SMS Gateway with Gammu technology is by developing patient online registration authentication system. The purpose of this study is to develop a patient online registration authentication system using SMS Gateway at Catur Ariwibowo Clinic. The development of this system is using waterfall method, with the following stages: requirements definition, system and software design, and implementation and unit testing. Functional testing used is Black Box Testing, this test was conducted to find out the system functionality. Researcher use questionnaire to test user satisfaction. Based on the functional test and user satisfaction that has been done, it can be concluded that the system is already running in accordance with its function and 82.56 percent of respondents are satisfied on the system that has been developed.
\end{abstract}

Keywords: SMS Gateway, authentication, waterfall method, Black Box Testing.

\section{Pendahuluan}

Autentikasi adalah proses verifikasi untuk menyatakan suatu identitas diri dari seorang user. Bentuk umum yang biasa digunakan untuk melakukan autentikasi menggunakan login ID/ username dan password, jika kombinasi keduanya benar maka client dapat mengakses ke sumber daya jaringan tertentu. Proses autentikasi dapat dianalogikan seperti seorang tamu yang datang ke rumah seseorang, sebelum tamu tersebut diperbolehkan masuk, tentu tuan rumah harus mengetahui tamu itu terlebih dahulu, jika manusia kenal dengan tamu tersebut, maka tamu tersebut pastinya akan dipersilahkan masuk dan sebaliknya [1].

Pelayanan kesehatan pada Klinik Dokter Catur Ariwibowo, yaitu pendaftaran pasien masih secara konvensional dengan melakukan pengarsipan dan pencatatan pada buku, seperti pencatatan pendaftaran berobat. Sehingga menggunakan banyak kertas untuk menyimpan arsip-arsip data pasien dalam lemari arsip.

Salah satu pemanfaatan teknologi SMS Gateway, penulis mengembangkan Sistem Autentikasi Pendaftaran Online Pasien Menggunakan SMS Gateway. Dengan adanya sistem tersebut dapat membantu pasien untuk melakukan pendaftaran dimana dan kapan saja. Selain itu, pasien juga tidak perlu khawatir akan kesalahan data yang dimasukkan karena terdapat proses autentikasi untuk memvalidasi kebenaran orang berdasarkan data yang dimasukkan. 
Sistem Informasi Pendaftaran Pasien Berbasis SMS Gateway telah dikembangkan pada Puskesmas Medeka Kota Palembang. Sistem tersebut digunakan untuk melakukan pendaftaran pasien dan mengurangi kondisi penumpukan antrian di ruang pendaftaran. Oleh sebab itu pada Tugas Akhir ini, peneliti mencoba untuk mengembangkan Sistem Autentikasi Pendaftaran Online Pasien pada studi kasus Klinik Catur Ariwibowo [2].

Pengembangan sistem ini, merupakan bagian dari kedua sistem besar yang digabung. Namun, pada skripsi ini tidak membahas tentang rekam medis dan hanya berfokus pada SMS Gateway dan rekap data pasien dalam bentuk grafik.

\section{Tinjauan Pustaka}

Gammu adalah service yang disediakan untuk membangun aplikasi berbasis SMS Gateway. Aplikasi SMS Gateway dengan Gammu adalah free. Ada dua mekanisme kerja dari Gammu yaitu sebagai aplikasi dan sebagai daemon. Gammu sebagai aplikasi akan bekerja ketika perintah Gammu dijalankan pada lingkungan shell beserta perintahnya disertakan sesuai fungsi yang diinginkan. Sedangkan Gammu sebagai daemon, ditandai dengan dijalankannya perintah smsd pada shell. Pada prinsipnya cara kerja Gammu yaitu menghubungkan modem/ponsel dengan PC. SMS yang diterima di modem/ponsel akan diambil oleh Gammu untuk dipindahkan ke dalam database yang telah diatur sebelumnya [3].

SMS Gateway merupakan sebuah sistem aplikasi yang digunakan untuk mengirim dan atau menerima SMS, dan biasanya digunakan pada aplikasi bisnis, baik untuk kepentingan broadcast promosi, dan lain-lain [4].

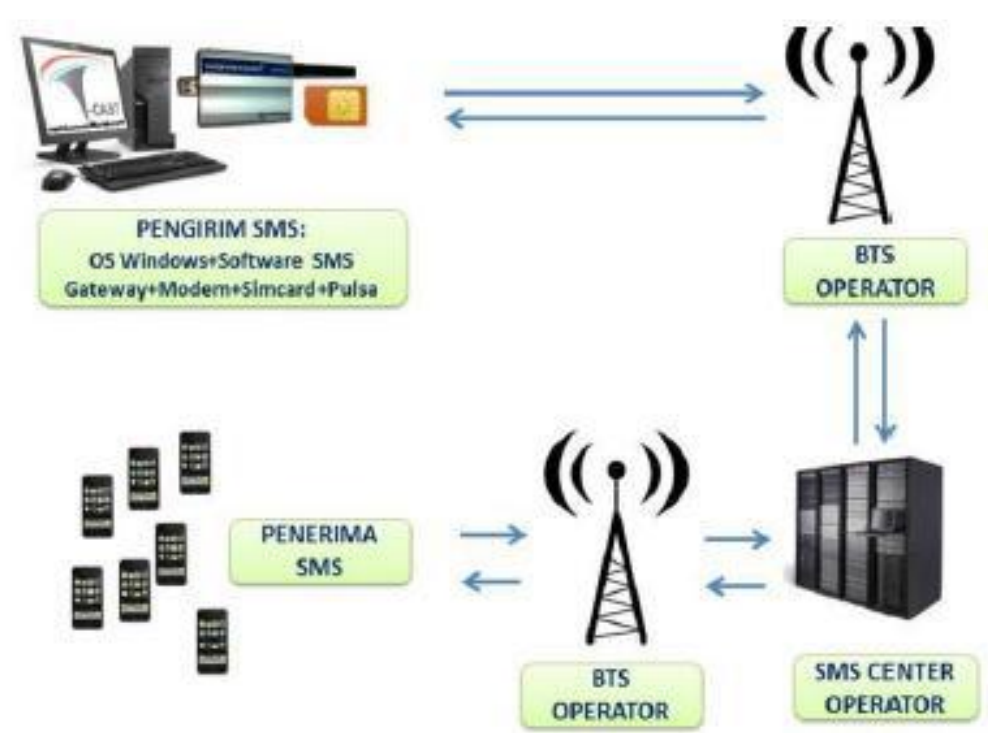

Gambar 1. Ilustrasi Konsep SMS Gateway [5].

Pada saat melakukan pengiriman pesan SMS dari Handphone (mobile originated) pesan tersebut tidak langsung dikirimkan ke Handphone tujuan (mobile terminated), akan tetapi dikirim terlebih dahulu ke SMS Center (SMSC), baru kemudian pesan tersebut diteruskan ke Handphone tujuan. Dengan adanya SMSC ini dapat diketahui status dari pesan SMS yang dikirim, apakah telah sampai atau gagal diterima oleh Handphone tujuan.

Apabila Handphone tujuan dalam keadaan aktif dan dapat menerima pesan SMS yang dikirim. Handphone tersebut akan mengirimkan kembali pesan konfirmasi ke SMSC yang menyatakan bahwa pesan telah diterima. Kemudian SMSC mengirimkannya kembali status tersebut kepada 
pengirim. Jika Handphone tujuan dalam keadaan mati, pesan yang dikirimkan akan disimpan pada SMSC sampai periode validity terpenuhi [6].

\section{Metodologi Penelitian}

Metode pengembangan yang digunakan pada penelitian ini yaitu metode Waterfall. Tahapan yang dilakukan pada metode Waterfall dapat dilihat pada Gambar 2.

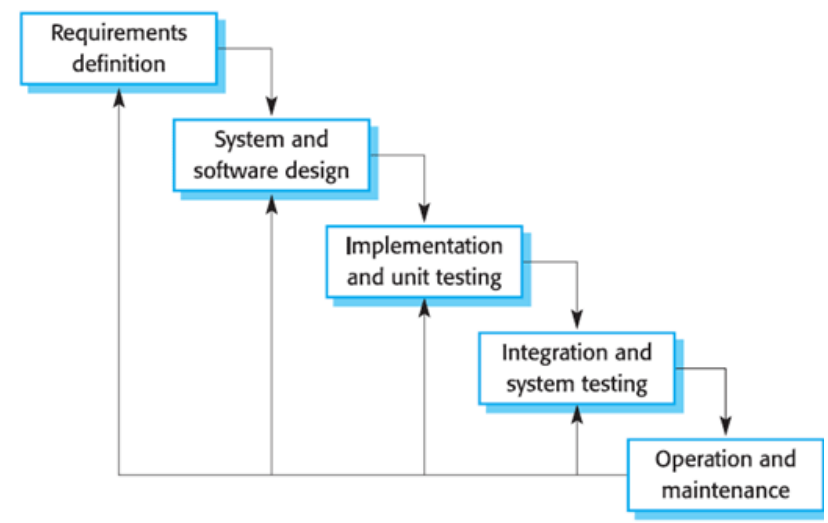

Gambar 2. Metode Waterfall [7].

Metode pengembangan sistem pada penelitian ini menggunakan metode Waterfall. Adapun tahap yang dilakukan yaitu :

\section{Definisi Kebutuhan}

Tahap ini dilakukan studi literatur dan komunikasi kepada pihak pengguna, mengenai proses bisnis klinik dan bagaimana sistem informasi yang diinginkan oleh pengguna.

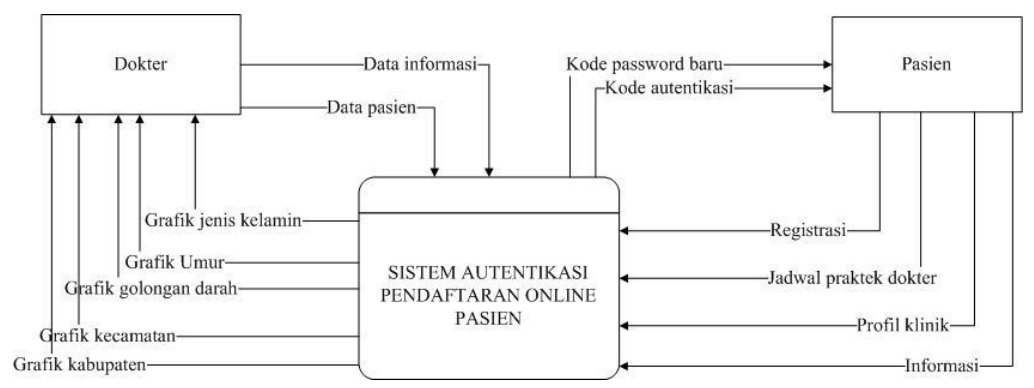

Gambar 3. Context Diagram.

2. Desain Sistem dan Perangkat Lunak

Pada tahap ini penulis membuat rancangan dari sistem yang akan dikembangkan meliputi Data Flow Diagram (DFD), Entity Relationship Diagram (ERD), dan pembuatan interface dari sistem yang dikembangkan. 
1. Data Flow Diagram (DFD).

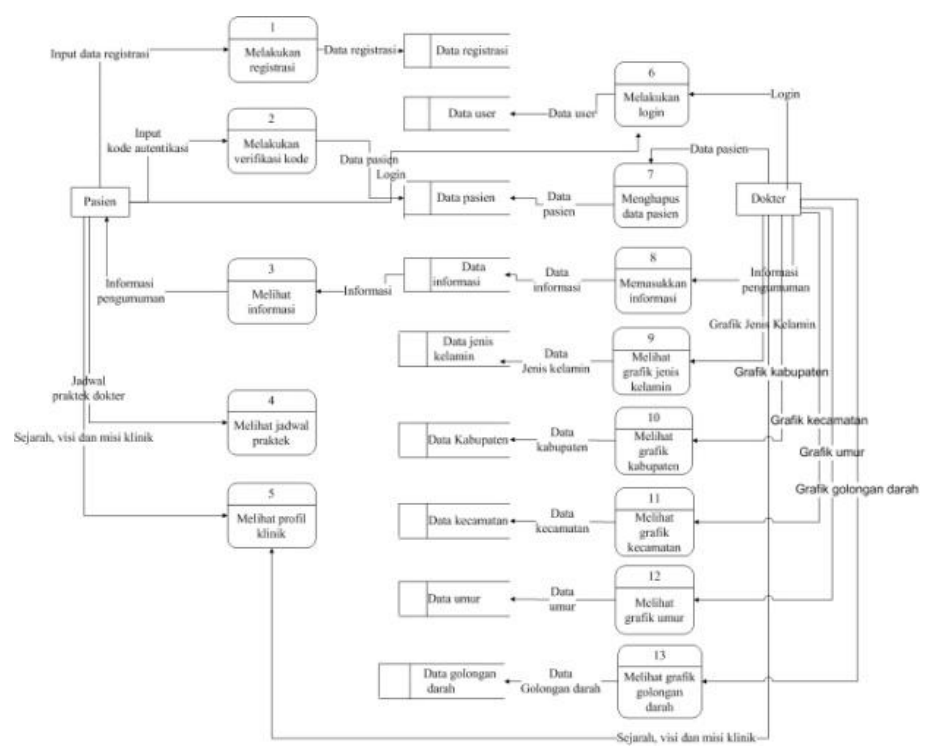

Gambar 4. Data Flow Diagram (DFD).

Gambar 4 menunjukkan Data Flow Diagram (DFD) dari sistem yang dikembangkan dan merupakan turunan dari Context Diagram. Terdapat dua external entity yaitu Pasien dan Dokter. Kedua pengguna dapat melakukan beberapa aksi seperti dapat dilihat pada Gambar 4.

2. Entity Relationship Diagram (ERD)

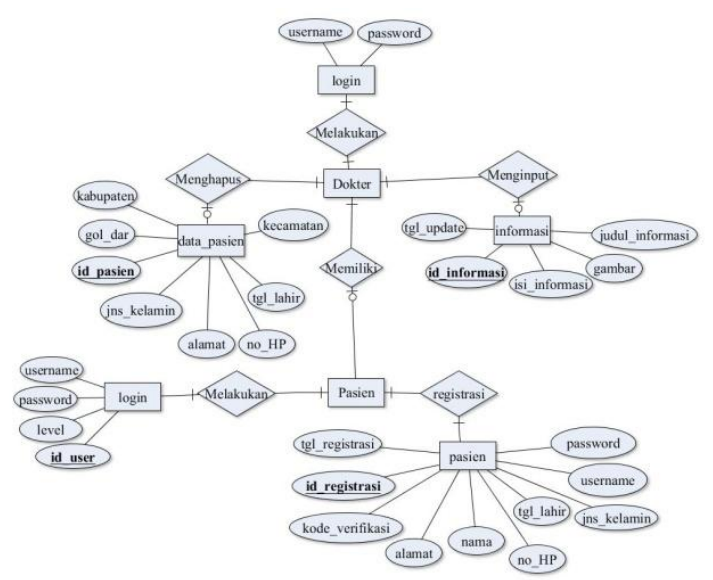

Gambar 5. Entity Relationship Diagram (ERD).

\section{Hasil dan Pembahasan}

\subsection{Implementasi}

Tahap ini dilakukan implementasi dengan membuat kode program menggunakan Bahasa PHP dan mengimplementasikan fitur SMS Gateway. Hasil dari tahap kode program ditunjukkan dengan beberapa tampilan dengan penjelasan masing-masing sebagai berikut: 
Vol 7 No.1, 2019

Jurnal Komputasi

C2019 Ilmu Komputer Unila Publishing Network all right reserve

1. Halaman Registrasi Pasien

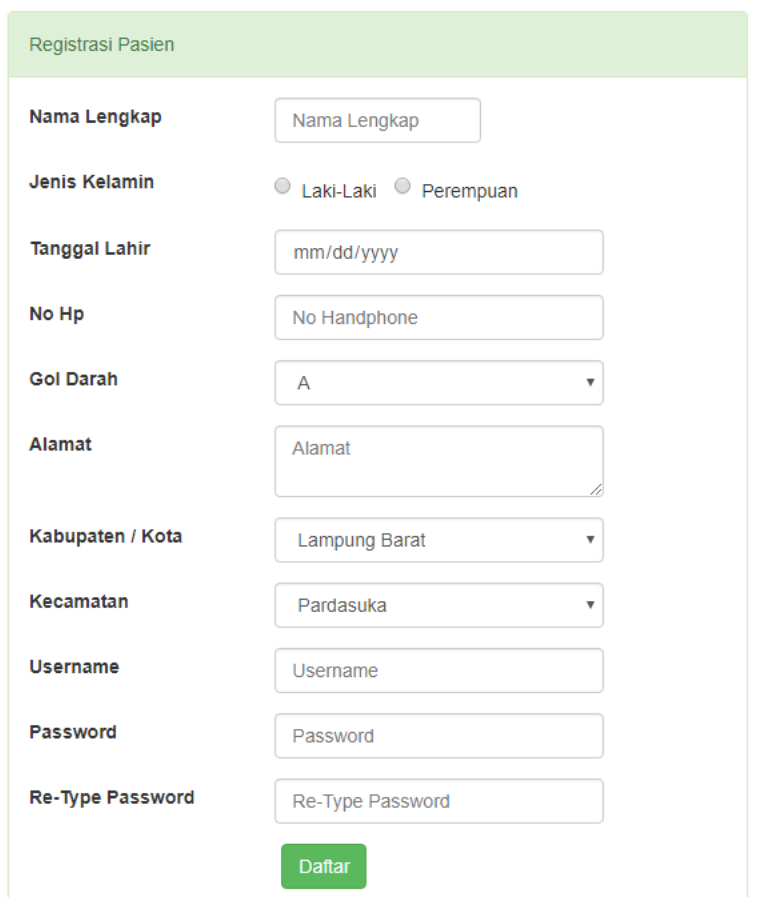

Gambar 6. Halaman Registrasi Pasien.

Gambar 6 menunjukkan halaman registrasi Pasien. Pada halaman ini pasien dapat melakukan input data saat melakukan registrasi.

2. Halaman Autentikasi Pasien

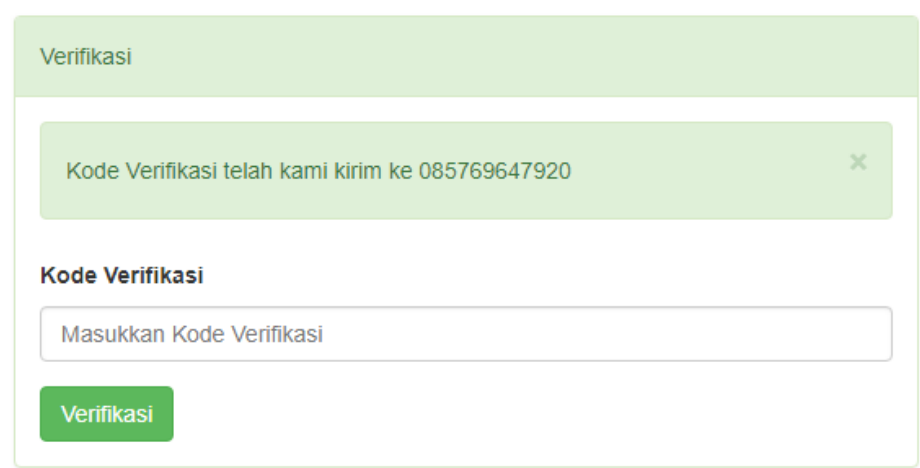

Gambar 7. Halaman Autentikasi Pasien.

Gambar 7 menunjukkan halaman autentikasi. Pada halaman ini Pasien dapat memasukkan kode autentikasi yang telah dikirim ke nomor Handphone yang dicantumkan saat melakukan registrasi. 


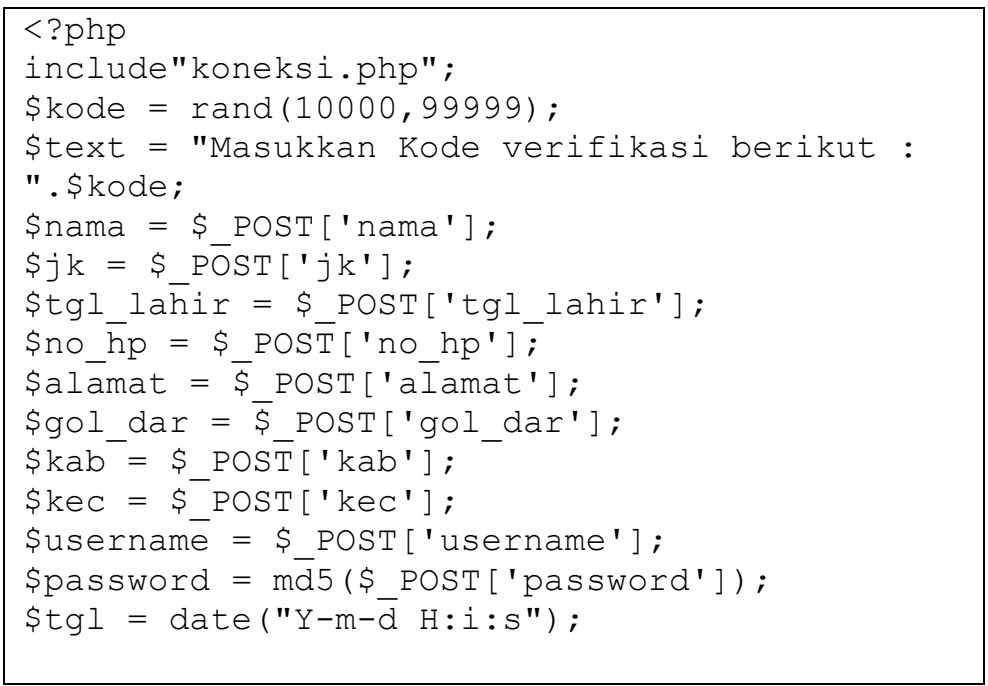

\section{Potongan Kode Program Pengiriman Kode Autentikasi.}

Potongan kode program pengiriman kode autentikasi merupakan source code untuk pengiriman kode dikirimkan ke nomor Handphone yang digunakan saat melakukan registrasi. Pengiriman kode bersifat random, dari angka 10000 sampai 99999.

\section{Halaman Reset Password Pasien}

\begin{tabular}{l} 
Reset Password \\
Silahkan masukkan No HP yang anda gunakan saat melakukan registrasi \\
Nomor HP \\
\hline Login
\end{tabular}

Gambar 9. Halaman Reset Password Pasien.

Gambar 9 menunjukkan halaman reset password. Halaman ini digunakan saat Pasien lupa dengan password yang telah dibuat. Kemudian sistem akan mengirimkan kode baru sebagai password baru Pasien

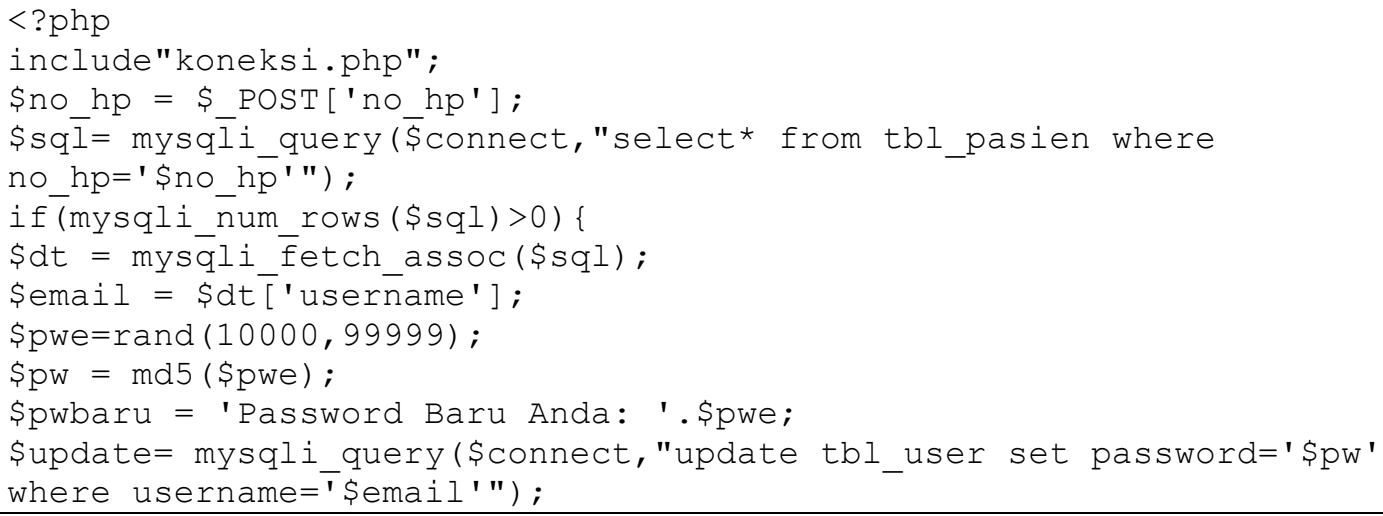




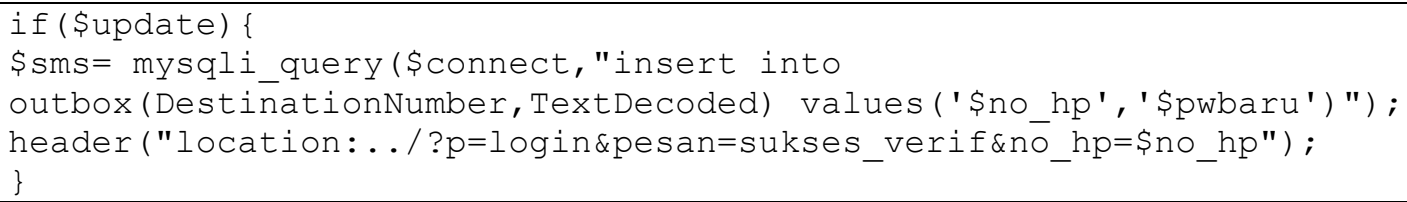

\section{Potongan Kode Program Pengiriman Password Baru.}

Potongan kode program pengiriman password baru merupakan source code untuk pengiriman kode yang dikirimkan ke nomor Handphone yang dimasukkan saat melakukan registrasi. Pengiriman kode password baru bersifat random seperti saat pengiriman kode autentikasi, yaitu dari angka 10000 sampai 99999.

4. Halaman Data Pasien (Dokter)

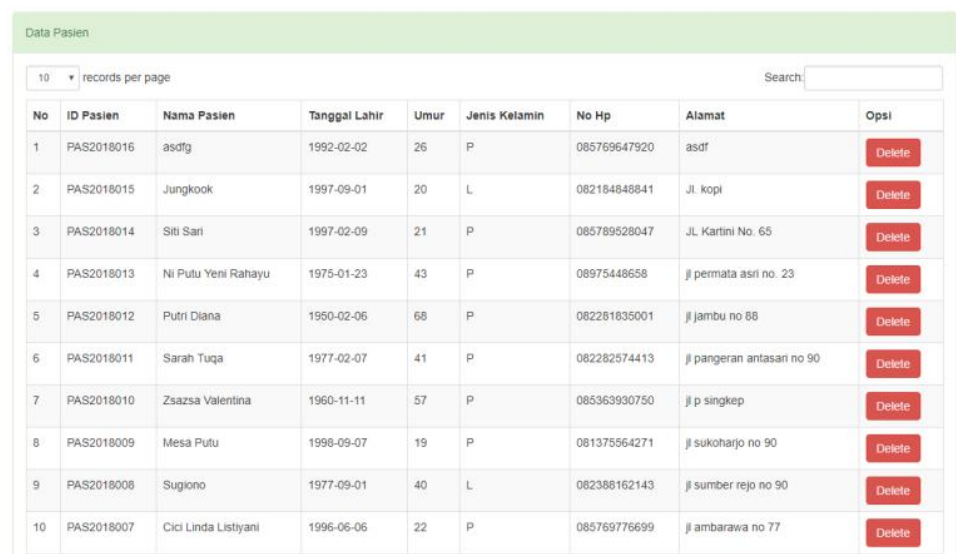

Gambar 11. Halaman Data Pasien (Dokter).

Gambar 11 merupakan halaman data pasien yang dikelola oleh Dokter. pada halaman ini Dokter dapat melihat seluruh Pasien yang terdaftar pada sistem. Selain itu Dokter juga dapat melakukan aksi hapus.

5. Halaman Rekap Jenis Kelamin

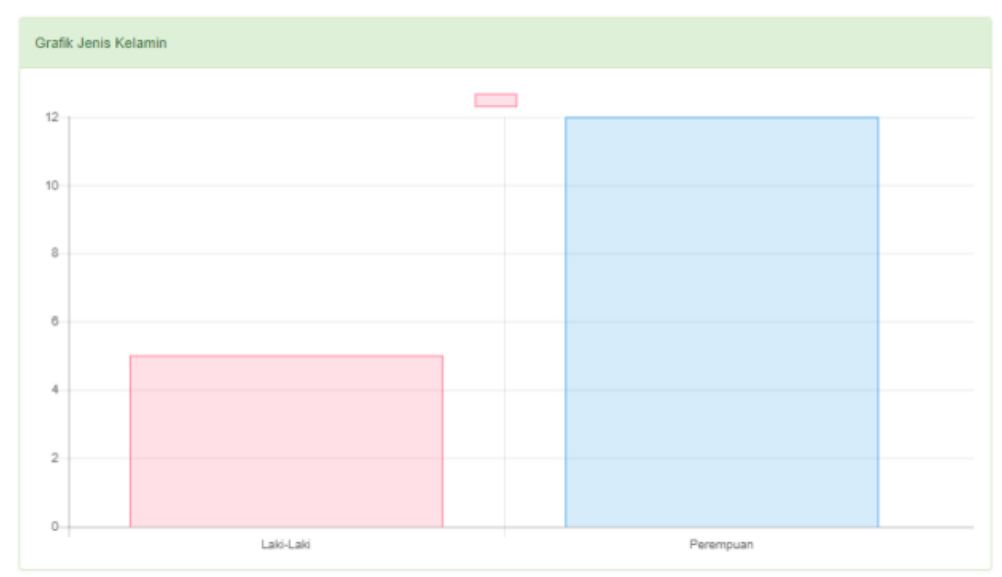

Gambar 12. Halaman Rekap Jenis Kelamin. 
Gambar 12 merupakan halaman rekap jenis kelamin yang dikelola oleh Dokter. Pada halaman ini Dokter dapat melihat jumlah pasien berdasarkan jenis kelamin dalam bentuk grafik.

6. Halaman Rekap Kecamatan

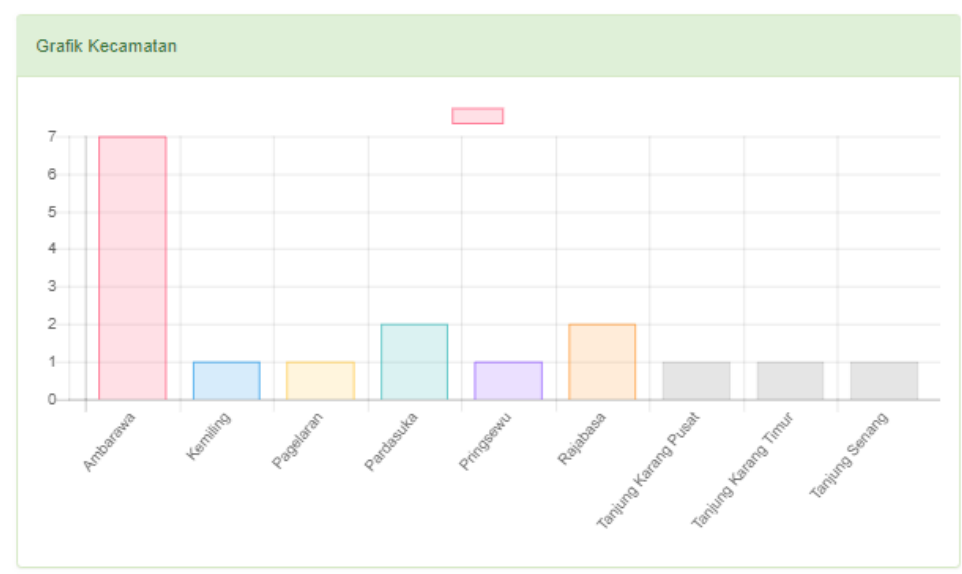

Gambar 13. Halaman Rekap Kecamatan.

Gambar 13 merupakan halaman rekap jenis kecamatan yang dikelola oleh Dokter. Pada halaman ini Dokter dapat melihat jumlah pasien berdasarkan asal kecamatan dalam bentuk grafik.

\subsection{Pengujian Sistem}

Pada penelitian ini, pengujian secara fungsional dengan menggunakan metode black box testing. Untuk pengujian sistem, dilakukan oleh 18 mahasiswa Universitas Lampung, satu mahasiswa Universitas Teknokrat Indonesia, dan satu mahasiswa IIB Darmajaya. Hasil dari pengujian sistem dengan menggunakan metode ini dapat disimpulkan bahwa secara keseluruhan sistem ini sudah berjalan dengan baik dan berhasil secara keseluruhan.

Selain itu pengujian kepuasan user juga telah dilakukan yaitu dengan menyebarkan kuisioner. Hasil dari pengujian tersebut yaitu $82,56 \%$ responden puas dengan sistem yang telah dikembangkan.

\section{Simpulan}

Berdasarkan penelitian mengenai Sistem Autentikasi Pendaftaran Online Pasien Pada Klinik Catur Ariwibowo Menggunakan SMS Gateway dapat disimpulkan sebagai berikut:

1. SMS Gateway telah berhasil digunakan sebagai fitur penunjang pendaftaran online Pasien,

2. Telah dibangun Sistem Autentikasi Pendaftaran Online Pasien Pada Klinik Catur Ariwibowo Menggunakan SMS Gateway

3. Telah dibangun sistem yang berguna untuk pengolahan data pasien dalam bentuk grafik. 
C2019 Ilmu Komputer Unila Publishing Network all right reserve

\section{DAFTAR PUSTAKA}

[5] Amelia, M. (2016). Sistem Monitoring Pengumpulan Getah Karet Berbasis Sms Gateway Pada Petani Karet Di Desa Surya Adi Kabupaten Oki Provinsi Sumatera Selatan, 7(1), $31-36$.

[4] Bororing, J. E., \& Janabadra, U. (2017). Aplikasi Pencarian Informasi Surat Tanda Nomor Kendaraan ( Stnk ) Berbasis Sms Gateway, (September).

[3] Jumri, J. P. (2012). Perancangan Sistem Monitoring Konsultasi Bimbingan AkademikMahasiswa dengan Notifikasi Realtime Berbasis SMS Gateway, 5.

[1] Kunang, Y. N., Darma, U. B., Yadi, I. Z., \& Darma, U. B. D. (2008). Berbasis Radius Server ( Studi Kasus WLAN Universitas Bina Darma ), (August), 25.

[7] Sasmito, G. W. (2017). Penerapan Metode Waterfall Pada Desain Sistem Informasi Geografis Industri Kabupaten Tegal, 2(1), 6-12.

[2] Ratnasari, D. (2015). Universitas Islam Negeri Raden Fatah, (11210052), 1-167.

[6] Wiharto, Y. (2011). Sistem Informasi Akademik Berbasis SMS Gateway, 1(1), 1-28. 